\title{
Neural bruise prediction models for fruit handling and machinery evaluation
}

\author{
P. Barreiro , V. Steinmetz , M. Ruiz-Altisent \\ ${ }^{a}$ ETSIA, Rural Engineering Department, Avda. Complutense s/n, 28040 Madrid, Spain \\ ${ }^{b}$ CEMAGREF, Genie Instrumental pour la Qtualite Agro-Alimentaire, \\ 361 Rue Jean Francois Breton 34033 Montpellier, France
}

\begin{abstract}
Neural bruise prediction models based on the degree of fruit damage of the most traded fruit species and varieties were developed for prediction of the fruits to be accepted or rejected. The prediction relied on European Community standards. Different models for both quasi-static (compression) and dynamic (impact) loads covering the full commercial ripening period of fruits were developed. A simulation process was developed for gathering the information on laboratory bruise models and load sensor calibrations for different electronic devices (IS-100 and DEA-1, for impact and compression loads, respectively). An evaluation method was also designed for acquiring and gathering the information on the mechanical properties of fruits and the loading records of the electronic devices. The evaluation system allowed for determination of the current stage of fruit handling processes and machinery.
\end{abstract}

Keywords: Load sensors; Network models; Bruise simulation; Decision support system

\section{Introduction}

The current state of the fresh fruit retail market in Europe is declining. Fresh fruit consumption may decrease due to the lack of quality in the markets. Recent research results (Kampp and Pedersen, 1990) have shown that less than $10 \%$ of the 
fruits titled class I followed the European Community (EC) standards mainly dite to the presence of mechanical damage. Fruit handling processes and mechanical equipment get more and more complex as new sensors and actuators are included for quality assessment. Therefore there is a need to evaluate standardization methods for fruits in order to objectively compare differences between the machineries that handle fruits. In this respect, electronic devices (equipment) have been developed (Halderson and Skrobacki, 1986; Brown et al., 1990; Baganz, 1992). However, mechanical properties of fruits have a great effect on the susceptibility of fruits to mechanical damage (Chen and Zongnan, 1981; Chen et al., 1987; Garcia and Ruiz-Altisent, 1988; Rodriguez et al., 1990; Ruiz-Altisent, 1990). Hence, gathering the information on the mechanical properties of fruits is necessary for the evaluation of machinery for handling and processing.

Until now some comparisons between electronic device measurement and mechanical properties of fruits have been made (Brown et al., 1989; Schulte et al., 1992, 1993; Sober et al., 1990). Every day a wider range of fruit varieties and storage treatments are used through the same machinery. Therefore, a wider link between the electronic devices and the mechanical properties of fruit is required.

Barreito and Ruiz-Altisent (1993) studied mechanical properties of fruits and used a statistical approach to develop bruise prediction models and evaluation methods. Neural networks (Robert et al., 1989; Ros et al., 1993; Steinmetz and Delwiche, 1993) were used to evaluate the adaptability of the developed bruise models.

Within this context, the objectives for the current study were:

1. To search for the optimal bruise prediction models,

2. to gather information on the mechanical properties of fruits and the electronic devices to simulate bruise appearance and

3. to design an evaluation method for determining the current state of the fruit handling process and machinery with respect to $\mathrm{EC}$ standards.

\section{Material and methods}

The most exported pome and stone species: Apple, pear and peach were used to develop bruise modelization. A trading study was conducted to select the most important fruit varieties: apple (Golden Delicious), pear (Conference and Doyenne du Comice) and peach (Maycrest and Springtime). Data recorded by Barreiro and Ruiz-Altisent (1993) where exhaustive research on fruit mechanical properties and bruise susceptibility was carried out, were employed in this study. The most common cold storage treatments and load types (compression and impact) were studied. Firmness as well as bruise susceptibility were mainly used.

Firmness was measured through non-destructive impacts using an instrument developed by Chen et al. (1985). Bruise susceptibility was measured based on compression using an INSTRON machine model 1122 where the maximum force was used as the loading level index. For impact bruise susceptibility assessment the impact firmness tester was also used. The loading level index was varied by 
changing the impact height. Finally a calibration test (Barreiro, 1994) was carried out in order to relate the loading level indices with maximum acceleration and electric resistance due to impact and compression of electronic devices. The electronic devices used were IS-100 and DEA-1 developed by Halderson and Skrobacki (1986) and Baganz (1992), respectively.

\subsection{Selection of variables for bruise modeling}

The first step for developing the bruise prediction models was to select the variable which would best represent bruise damage. The EC standards give the maximum surface damage allowable for each quality class, $1 \mathrm{~cm}^{2}$ and $0.5 \mathrm{~cm}^{2}$ for pome and stone fruits, respectively. However, the external surface damage depends on the size of surface contact between two bodies during loading and also on the radius of curvature of the bodies in contact (Horsfield et al., 1972). On the other hand, the smaller the radius of curvature, the deeper the bruise is. As a result it was possible to find bruises having equivalent bruise volume but different bruised external surfaces leading to differences in quality evaluation. Therefore, a new parameter (bruise section), was created to include these effects representing twice the internal bruised section area. Thus the units for the bruised section arc the same as for the bruised external surface (mm).

As for the selection of the explicative variables for bruise modelization, it was decided to apply the parsimony principle on the machinery to be employed. Only a firmness sensor and an electronic device were used so that the process and machinery evaluation could easily be carried out. Based on studies by Chen et al. (1987), Chen and Ruiz-Altisent (1994), Correa et al. (1992), Jarén et al. (1992), Rodriguez et al., 1990; Ruiz-Altisent (1990), Barreiro and Ruiz-Altisent (1993) it was decided that a different bruise model be used for each variety and loading type. Each bruise model would include as explicative variables the following magnitudes: Fruit firmness (measured by non-destructive impacts), loading level and storage treatment and/or any combinations of them; explicative variables are all correlatively numbered (Table 1$)$.

\subsection{Model evaluation}

As a first step, a stepwise linear regression analysis was carried out to check whethet the selected variables were significant for bruise prediction. Afterwards, different neural approaches for bruise prediction were carried out. The bruise prediction models were compared using the correlation coefficient between bruise prediction and observation. Bruise prediction models were also evaluated based on the EC standards. An error below the EC tolerance ( $10 \%$ for class I) was used also as a criterion for model acceptation.

Comparison between fruit classification under the EC standards for predicted and observed damage resulted in the categories shown in Fig. 1. In Fig. I A, B, C and $D$ are percentages of unclassified, weli classified, non detected damages and overdetected damages, respectively. Both $\mathrm{C}$ and $\mathrm{D}$ should be below $10 \%$ for the 
Table 1

Variables employed for the neural approaches

\begin{tabular}{|c|c|c|}
\hline & Variable & $\begin{array}{l}\text { Numerical } \\
\text { identification }\end{array}$ \\
\hline \multirow[t]{10}{*}{ Non-destructive impact for firmness assessment } & $\begin{array}{l}\text { FZI, Maximum impact } \\
\text { force }(\mathrm{N})\end{array}$ & 1 \\
\hline & $\begin{array}{l}\text { DFI, Maximum impact } \\
\text { deformation }(\mathrm{m})\end{array}$ & 2 \\
\hline & TPI, Impact duration (s) & 3 \\
\hline & FZVDFI $(\mathrm{N} / \mathrm{m})$ & 4 \\
\hline & FZVTPI $(\mathrm{N} / \mathrm{s})$ & 5 \\
\hline & DFI $/$ TPI $(\mathrm{m} / \mathrm{s})$ & 6 \\
\hline & FZI*DFI (Nm) & 7 \\
\hline & $\mathrm{FZI} 2 / \mathrm{TPI}\left(\mathrm{N}^{2} / \mathrm{s}\right)$ & 8 \\
\hline & FZI/DFI2 $\left(\mathrm{N} / \mathrm{m}^{2}\right)$ & 9 \\
\hline & FZI*TPI2(Ns $\left.{ }^{2}\right)$ & 10 \\
\hline \multirow[t]{2}{*}{ Loading level } & HI, Impact height (m) & 11 \\
\hline & $\begin{array}{l}\text { FZC, Maximum } \\
\text { compression force (N) }\end{array}$ & 12 \\
\hline \multirow{3}{*}{$\begin{array}{l}\text { Combination of impact firmness and loading level } \\
\text { variables }\end{array}$} & FZCDFVFZI (m) & 13 \\
\hline & HIDFVFZI (ms) & 14 \\
\hline & FZIDFVFZC (m) & 15 \\
\hline Storage treatment type & Dimensionless & 16 \\
\hline
\end{tabular}

model to be acceptable. The pertenance of a predicted damage to a group was defined using the whole confidence interval at a $5 \%$ level of significance. A prediction had to show the same classification as the observed damage for the whole confidence interval to be considered well classified. The percentage of well

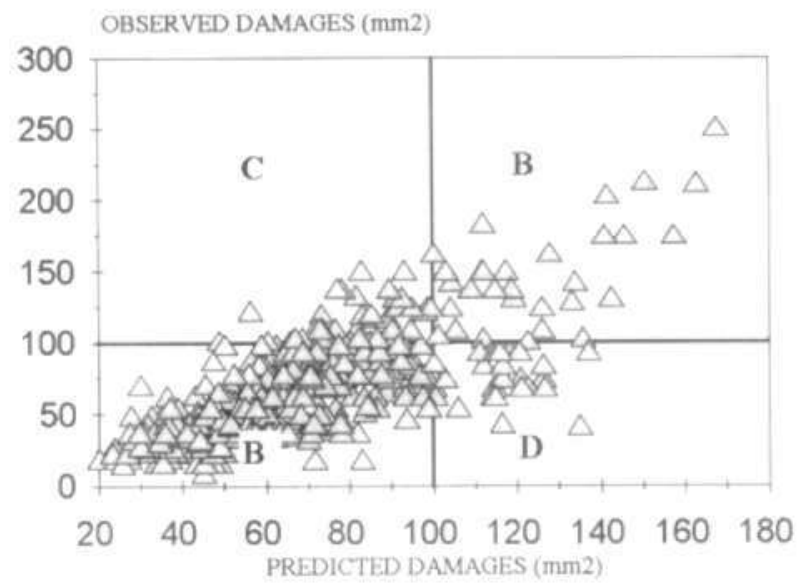

Fig. 1. Comparison between fruit classification for predicted and observed damages for the impact bruise modeling in Conference pears $(r=0.78, n=480)$. 
classified predictions increased with decreasing confidence interval (that is increasing model adjustment). Whenever the confidence interval was between acceptable or rejectable (below and above the EC limit) the fruit was considered unclassified.

\subsection{Neural network approach}

A sigmoid function was used for bruise prediction. The function was obtained from a biological model and it can be used in case of non linear relationships. The number of iterations required for training the neural network until convergency were fixed empirically at $\mathbf{4 0 0 0 0}$ for pome fruits and at 20000 for stone fruits. There were about $30 \%$ more individuals for: the pome than for the stone fruit varieties. The test set data for the neural network contained about half the number of samples of the training data set. The test data were obtained from the second repetition of the 1993 season's tests. The test data was not used during training. This way, it was possible to determine the models robustness by comparing the coefficient of determination for the training and the testing data. The evaluation of the samples classification under the EC standards was used only for the training set as few samples may lead to biased results.

Whenever it was not possible to generalize the results when all data for each model were used for neural network approaches, training data samples were specially selected. Then the neural network was tested to check if it could yield better results or not. In the second method, it was necessary to find out the sections where learning was low and to build a network covering that range of data. Once the low learning sections had been noted a 'minimal distance classifier' was used to determine the network under which unknown individuals should be tested.

The 'minimal distance classifier' compares each observation of a training set with an unknown damage to be predicted in terms of an euclidean distance. The euclidean distance is calculated considering as many spatial dimensions as explicative variables are used for bruise modelization. The minimal euclidean distance between a known and an unknown damage allows to decide which type of neural network solution should be used for damage prediction.

\section{Results for bruise prediction models}

Neural approaches were carried out using the Neuralworks Professional II plus software.

The main description of the explicative variables that where tested for bruise modeling is presented in Table 1. A stepwise linear regression analysis was performed on the variables 1-16 in order to find out the significance level for bruise prediction. The variables selected (Table 2) showed a significance level below $5 \%$.

With the variables shown in Table 2, new general and special networks were built (Table 3) searching for non-linear optimization. The general networks covered the full commercial maturity stage of fruits. As for the special networks, in most cases bad learning was obtained for observed damage above twice the EC limit. As this 
Table 2

Variables selected through stepwise lineat regression analysis

\begin{tabular}{lll} 
Model & & \\
\hline Variety & Compression & Impact \\
\hline Conference & $4,5,8,9,12,13,16$ & $4,7,8,11,14,16$ \\
Doyenne du Comice & $2,4,12,13,15,16$ & 11,16 \\
Golden Delicious & $4,12,16$ & $4,11,16$ \\
Maycrest & $4,10,12,13,16$ & $3,4,11,14,16$ \\
Springtime & $2,4,6,9,12,13,16$ & $2,3,4,8,11,14,16$
\end{tabular}

Numbers refer to the variables defined in Table $\mathbf{t}$.

value is quite high, the special net was trained only for an observed damage size twice below the EC limit. Any unknown damage to be classified would be submitted to a 'minimum distance classifier'. The decision would be based on the observed damage of the nearest neighbour.

Table 3

Final results for the neurai approaches

\begin{tabular}{|c|c|c|}
\hline \multicolumn{3}{|l|}{ Model } \\
\hline Variety & Compression & Impact \\
\hline Conference & $\begin{array}{l}\text { Special } \\
r=0.78 ; n=480 \\
C=5.4 \\
D=6.9\end{array}$ & $\begin{array}{l}\text { General } \\
r=0.82 ; n=480 \\
C=7.5 \\
D=2.3\end{array}$ \\
\hline Doyenne du Comice & $\begin{array}{l}\text { Special } \\
r=0.72 ; n=400 \\
C=8.5 \\
D=4.8\end{array}$ & $\begin{array}{l}\text { General } \\
r=0.79 ; n=400 \\
C=6.8 \\
D=5.2\end{array}$ \\
\hline Golden Delicious & $\begin{array}{l}\text { General } \\
r=0.82 ; n=456 \\
C=7.5 \\
D=4.8\end{array}$ & $\begin{array}{l}\text { General } \\
r=0.88 ; n=456 \\
\mathrm{C}=0.7 \\
\mathrm{D}=7.7\end{array}$ \\
\hline Maycrest & $\begin{array}{l}\text { Special } \\
r=0.79 ; n=228 \\
C=3.9 \\
D=2.7\end{array}$ & $\begin{array}{l}\text { Special } \\
r=0.7 \mathrm{I} ; n=228 \\
\mathrm{C}=7.9 \\
\mathrm{D}=3.5\end{array}$ \\
\hline Springtime & $\begin{array}{l}\text { Special } \\
r=0.81 ; n=238 \\
C=1.7 \\
D=9.2\end{array}$ & $\begin{array}{l}\text { Special } \\
r=0.80 ; n=238 \\
\mathrm{C}=3.4 \\
\mathrm{D}=9.7\end{array}$ \\
\hline
\end{tabular}

$F$ is the correlation coefficient between predicted and observed dantages, $n$ is the number of samples, $C$ and $D$ are the classification errors expressed as percentages; $C$ and $D$ should be below $10 \%$ to accept the model; the conditions modeiled cover the full commercial ripening period of fruits. 
Table 4

Final architecture for the neural approaches

\begin{tabular}{lll}
\hline Variety & Compression & Impact \\
\hline Conference & $7-1-1$ & $6-0-1$ \\
Doyenne du Comice & $6-0-1$ & $2-0-1$ \\
Golden Delicious & $3-0-1$ & $3-0-1$ \\
Maycrest & $5-1-1$ & $5-0-1$ \\
Springtime & $7-0-1$ & $7-0-1$ \\
\hline
\end{tabular}

The digits refer to the number of neurons belonging to the input, the hidden and the output layers, respectively.

The bad learning area was around the EC acceptation threshold for only the compression and impact models of Maycrest. This case was difficult as the threshold area was the most important one for final machinery evaluation. Therefore, it was decided to train the general network. Afterwards, a minimal distance evaluation would be made in order to know whether the damages to be predicted belonged to the $\mathrm{EC}$ acception threshold area or not. In the case of belonging to this area, a special network would be made to arrive at a final response. The final results for the neural approaches are shown in Table 3. The neural network architecture is described in Table 4.

\section{Results for the bruise simulation process}

It was necessary to relate the laboratory loading levels with levels commonly applied to fruits during handling processes and machinery grading. Lately, simulated electronic products (SEP) have been developed in order to perform the above task (Halderson and Skrobacki, 1986; Brown et al., 1990). Therefore, a calibration test was carried out for an IS-100 impact sensing device as well as for a DEA-1 compression sensing device (Barreiro, 1994). In both cases a calibration equation relating the laboratory loads and the electronic devices parameters was developed.

A calibration equation for predicting the impact drop height as the maximum acceleration registered by the electronic device was developed, the results showed a correlation coefficient of 0.98 for 127 samples (calibration limits $30-160 \mathrm{~g} \mathrm{~m} / \mathrm{s}^{2} ; \mathrm{g}$ refers to gravity acceleration $9.8 \mathrm{~m} / \mathrm{s}^{2}$ ).

A calibration equation was also determined for predicting the maximum force during compression based on the electrical resistance registered by the electronic device. The results showed a correlation coefficient of 0.94 for 252 samples (calibration limits $20-0.4 \mathrm{~K} \Omega$ ).

Finally, a simulation was carried out (Figs. 2 and 3), where the load threshold necessary to cause damage above the class I EC limit is 100 and $50 \mathrm{~mm}^{2}$ for pome and stone fruits, respectively, was calculated. The load limit was measured as the maximum acceleration during impact simulation and as the electrical resistance during compression simulation. 
The main results obtained for the bruise simulation process can be summarized as follows:

- There is a great effect of fruit firmness evolution during storage on bruise susceptibility for Conference pears (Fig. 2) as well as for peaches and apricots. Firmness evolution did not show this effect for Golden apples (Fig. 3) or Decana pears.

- The effect of fruit firmness evolution on bruise susceptibility is always higher for compression than for impact loads.

- The reference impact loading threshold (damage above the EC limit) for pome fruits reaches $70 \mathrm{~g}$ while it decreases to $50 \mathrm{~g}$ when working with stone fruits. These reference values change along the commercial ripening period depending on variety.

- The reference compression loading threshold (damage above the EC limit) for pome fruits reaches $5 \mathrm{~K} \Omega$. Stone fruits show higher compression susceptibility being their loading threshold $20 \mathrm{~K} \Omega$ (note that the electrical resistance decreases with increasing loading level).

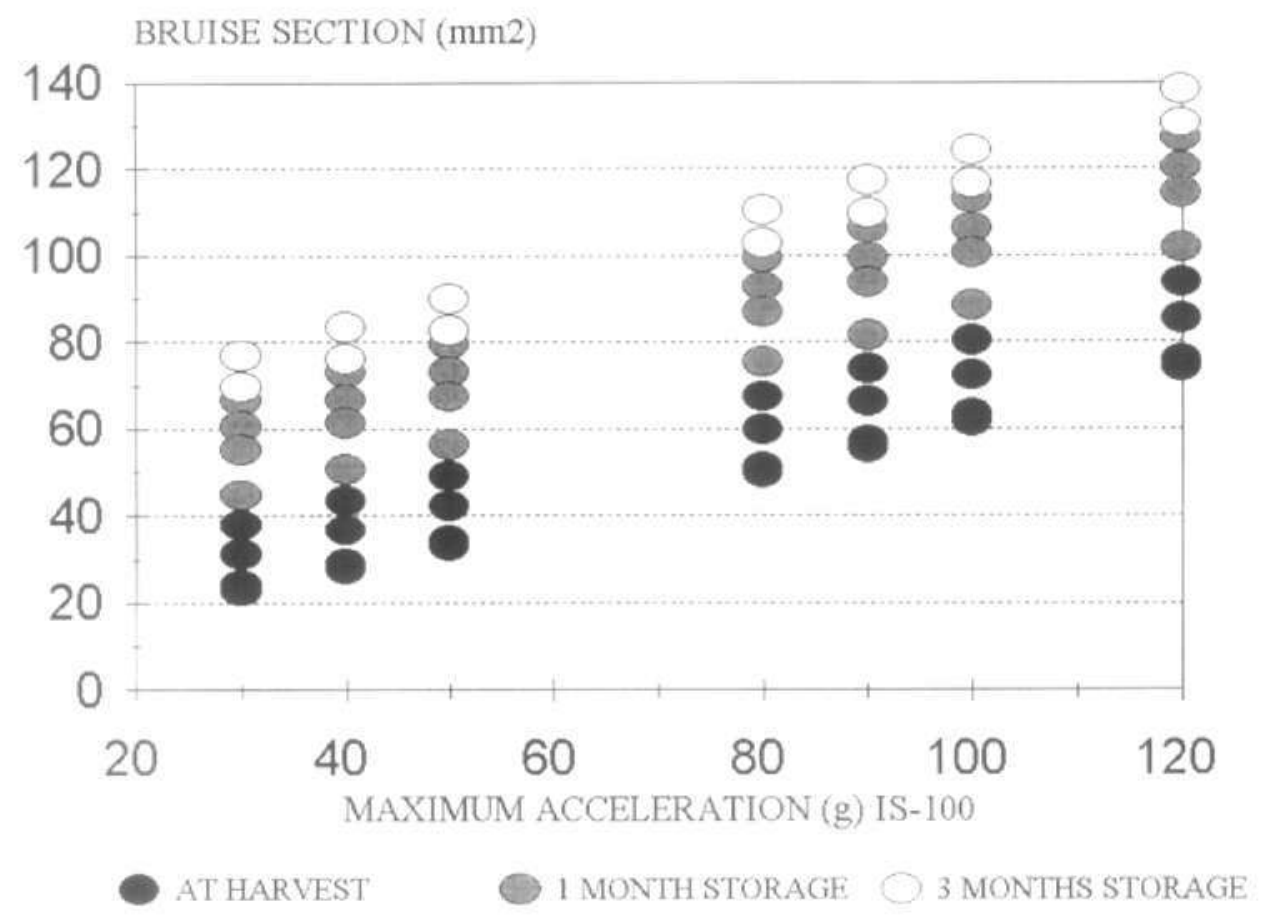

Fig. 2. Impact bruise simulation for Conference pears. A great effect of firmness evolution on bruise susceptibility is shown. 
BRUISE SECTION (mm2)

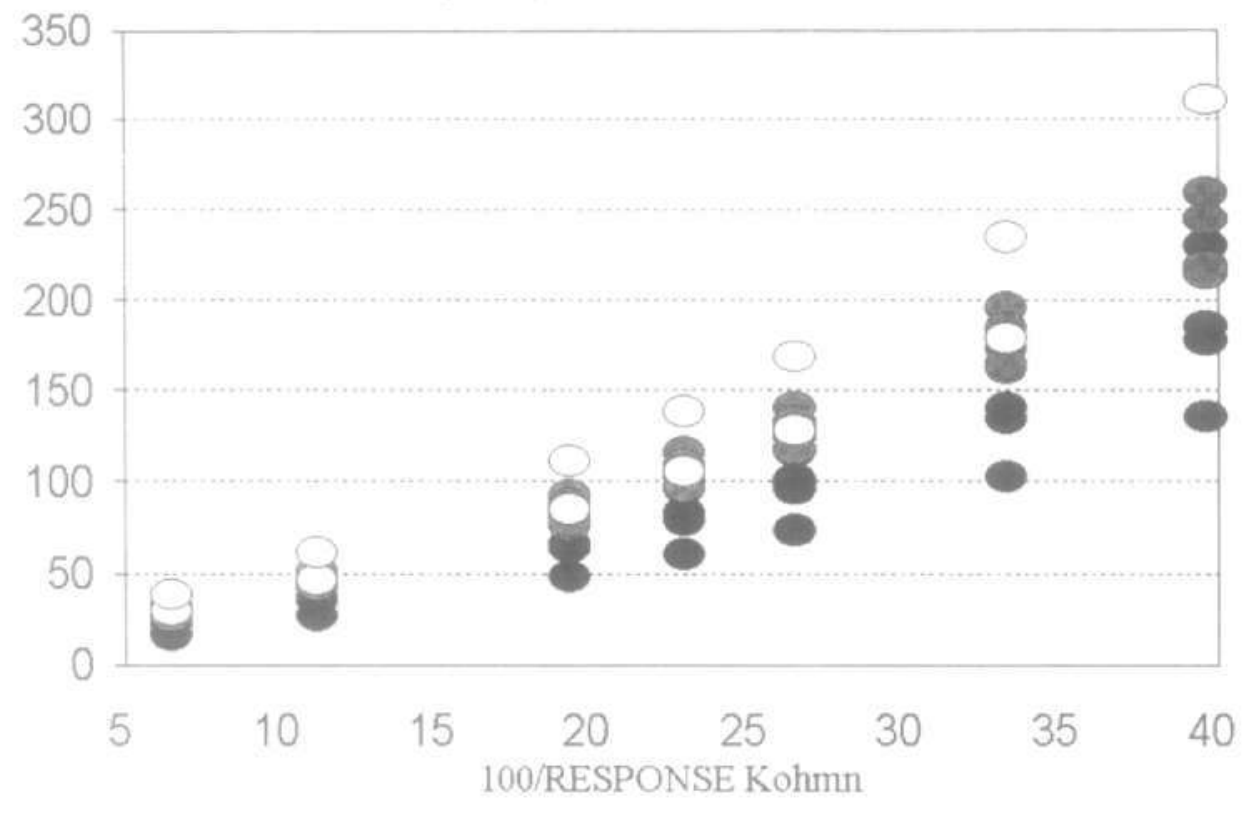

AT HARVEST

1 MONTH STORAGE

3 MONTHS STORAGE

Fig. 3. Compression bruise simulation for Golden apples.

\section{Results for handling process and machinery evaluation}

Once an acceptable solution (classification error below the EC tolerance level) had been found for each bruise prediction model, an evaluation methodology for handling equipment was designed. This evaluation system consisted of a decision system to aid growers on the knowledge of their procedures and machinery qualities by gathering the information on fruit firmness and storage treatments and relating it with the records obtained with the electronic devices (IS-100 and DEA-1) for bruise prediction.

Four classes of load levels were created for evaluation: Acceptable loads (AC) whenever predicted damage is between $0-80 \%$ of the EC limit, low risk loads (LR) for predicted damages between $81-90 \%$ of the EC limit, high risk loads (HR) for predicted damages between $91-99 \%$ of the EC limit and rejectable loads (RJ) for predicted damages equal or higher than the EC limit.

After defining the above classes, it was necessary to design the evaluation method. As it has already been mentioned, both devices (impact tester and electronic sensors) are used for the evaluation. The electronic devices record the information on the loading levels. However, the number of loading levels registered can be very high, as well as the time needed to process this information. Using the 
maximum loading level, the process gets faster but the amount of information is reduced. Therefore, it was decided to employ the four maximum loads $\left(\mathrm{L}_{\mathrm{i}}\right)$ corresponding to each quartile (qi) of the whole load histogram as a loading selection criteria. The number of processed samples is four times the number of fruits (four loads per fruit). Bruise prediction is based on these data obtaining as many damage predictions as processed samples (the full procedure is shown in Fig. 4). Using these results two different evaluations were designed: General evaluation and deficient process or machinery elements assessment.

\subsection{General evaluation}

A single fruit needs only a single damage above the limit to be rejected. For this reason the worst damage prediction per fruit was used to find the potential rejectability of fruits. As there are four different classes of loads defined, the results will also be divided in four categories: $\mathrm{AC}$ as the percentage of acceptable fruits, LR as the percentage of fruits under low rejectability risk, HR as the percentage of fruits under high rejectability risk and $R J$ as the percentage of rejectable fruits.

The evaluation criteria were defined according to the EC tolerance $(10 \%$ in number or weight of fruits for class I). Whenever the percentage of fruits classified as rejectable or under high rejectability risk is above $10 \%$, a revision or replacement of the concerned process or machinery element is necessary. Also, if the percentage of fruits under any rejectability risk is above $20 \%$ a revision is required.

\subsection{Deficient process or machinery element assessment}

Each of the four selected loadings were studied using the different percentages of AC, LR, HR and RJ fruits obtained.

A decision system for deficient process or machinery element assessment was created as follows:

1. If the four $\mathrm{L}_{\mathrm{i}}$ lead to a further revision, all the records of the electronic devices above the minimum $L_{\dot{f}}$ are identified as critical points requiring improvement. Once the element improvement is made, the evaluation procedure is repeated.

2. If any of the four $L_{i}$ is within the tolerance criteria, an interpolation for the threshold loading level determination is made. As before, all the records of the electronic devices above the threshold are identified. After improving the elements, the evaluation procedure is repeated,

3. If all the four $\mathrm{L}_{i}$ are within the tolerance level the final evaluation is positive. Therefore, the handling process or mechanical equipment is acceptable with respect to the $\mathrm{EC}$ standards.

\section{Conclusions}

Using linear and non-linear regressions as well as feed forward neural networks bruise prediction models have been built, for the main traded species and varieties of fruits: Apple, pear and peach. 


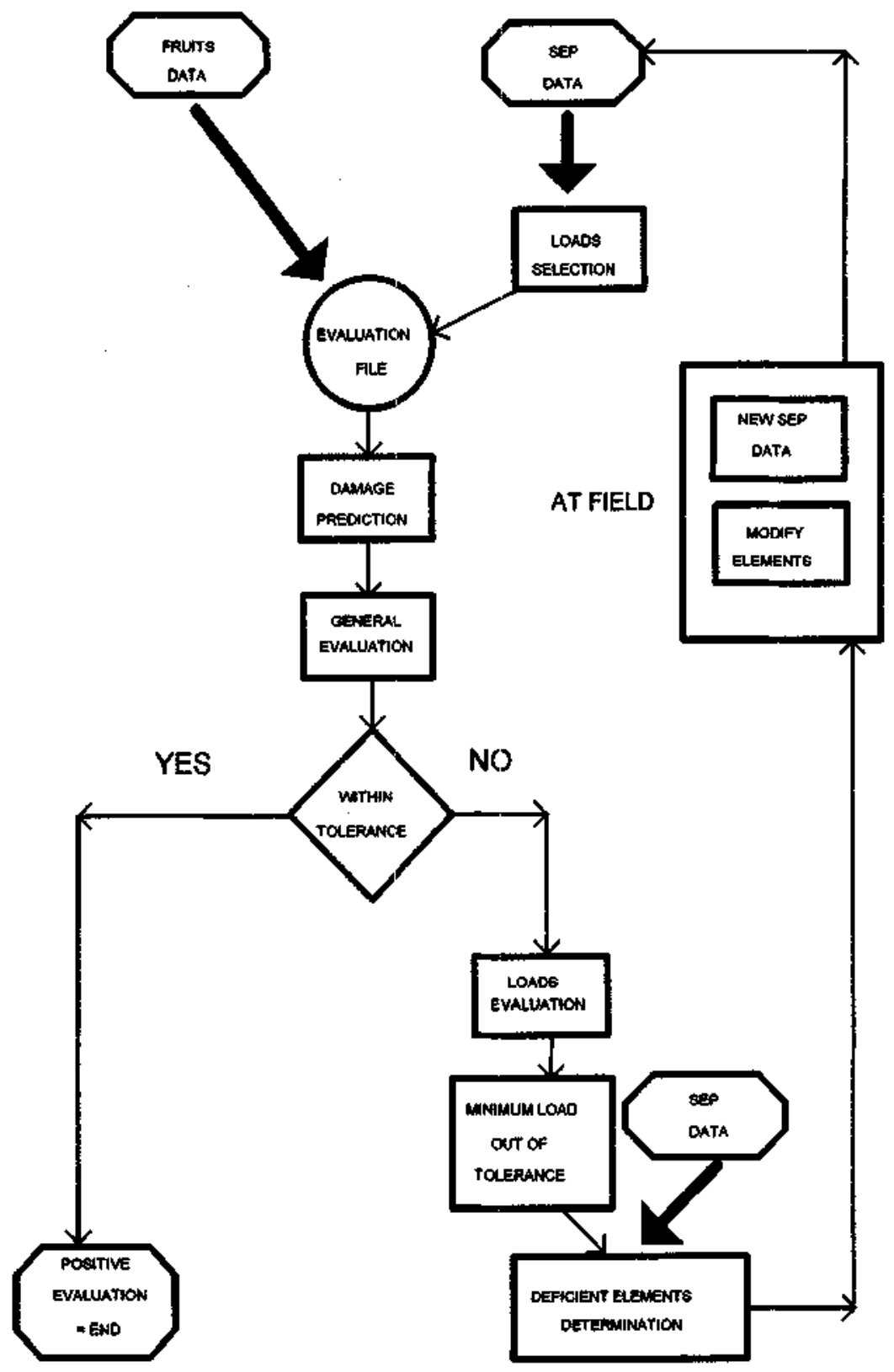

Fig. 4. Evaluation algorithm for fruit handling processes and mechanical equipments. The information on fruit firmness, storage treatment and electronic devices accumulated.

The bruise prediction models enable one to classify mechanical damages (as acceptable or rejectable) based on the EC standards with errors (undetected or overdetected damages) within the $\mathrm{EC}$ tolerance threshold of $10 \%$. The prediction 
models gather the information about bruise susceptibility evolution of fruits at harvest, cold storage and subsequent ripening at room temperature; the full commercial ripeness range is covered within the models.

The prediction models integrate also information about different loading types (compression or impact) allowing simulation of the effect of loading under different fruit bruise susceptibility conditions.

A calibration testing was performed to introduce electronic products information (IS-100, DEA-1) within the bruise prediction models. A simulation process was carried out for gathering the information on bruise models and impact and compression sensing devices (IS-100, DEA-I).

An evaluation of handling processes and machinery equipment as well as a decision system was developed to determine current stage of fruit handling processes in relation to fruit physical quality.

\section{Acknowledgements}

CAMAR EC Project No. CT91-0206: Quality of fruits: Engineering research for improving the quality preservation during pre and post harvest operations. The Fruit Cooperative of Montoliu (Lérida) and specially to Jaume Roque Calzada for their collaboration in pome fruits research. ANECOOP (Valencia) for its cooperation in peach research as well as handling process and machinery evaluation.

\section{References}

Baganz, K., 1992. 25 years experience with the Bornim Instrumented sphere. Proceedings of the Third International Symposium on Fruit Nut and Vegetable Harvesting Mechanization. Denmark, Sweden, Norway, pp. 163-164.

Barreiro, P., Ruiz-Altisent, M., 1993. Bruise susceptibility in pome fruits under different loading and storage conditions. Fourth International Symposium on Fruit Nut and Vegetable Production Engineering Mechanization, Valencia/Zaragoza. Paper No. 935.22.

Barreito, P., 1994. Modelos para la simulacion de danos mecanicos, y desarrolio de un algoritmo de evaluacion de maquinaria para los principales cultivares de albaricoque, manzana, melocoton y pera (Modeis for the simulation of mechanical damages and algorithm development for machinery evaluation uder the main apricot, apple, peach and pear varieties). PhD Thesis, ETSI Agronomos, Universidad Politecnica de Madrid.

Brown, G.K., Burton, C.L., Sargent, S.A., Schulte-Pason, N.L., Timm, E.J., Marshall, D.E., 1989. Assessment of apple damage on packing lines. Appl. Engin. Agri. 5 (4), 47S-484.

Brown, G.K., Schulte-Pason, N.L., Timm, E.J., 1990. Impact classifcation using the Instrumented Sphere. ASAE paper No, 90-6001.

Correa P., Ruiz-Altisent, M. and De la Plaza, J.L., 1992. Physical parameters in relation to physiological changes of avocado during ripening $\left(20^{\circ} \mathrm{C}\right)$ and cold storage $\left(6^{\circ} \mathrm{C}\right)$ in different conditions. Int. Conf. Agri. Mechanization, Uppsala, Paper No. 9211-16

Chen. P., Zongnan, S., 1981. Impact parameters related to bruise injury in apples. ASAE paper No. 81-3041.

Chen, P., Tang, S., Chen, S., 1985. Instrument for testing the response of fruits to impact. 260 A.SAE paper No. 85-3537. 
Chen, P., Ruiz-Altisent, M., Lu, F., Kader, A.A., 1987. Study of impact and compression damage on Asian pears. Trans. ASAE 30 (4), 1193-1197.

Chen, P., Ruiz-Altisent, M., 1994. Effect of impacting mass on firmness sensing of fruits. ASAE paper No. 93-6542.

Garcia, C., Ruiz-Altisent, M., 1988. Impact parameters related to bruising in selected fruits. ASAE paper No. 88-6027.

Halderson, J.L., Skrobacki, A., 1986. Dynamic performance of an impact telemetry system. ASAE paper No. 86-3030.

Horsfeld, B.C., Fridley, R.B., Claypool, L., 1972. Application of theory of elasticity to the design offruit harvesting and handling equipment for minimum bruising. Trans. ASAE 15 (4), 746-750.

Jarén C., Ruiz-Altisent, M., Perez de Rueda, R., 1992. Sensing physical stage offruits by their response to non-destructive impacts. Int. Conf. Agri. Mechanization, Uppsala 1992 paper No. $9111-113$.

Kampp, J., Pedersen, J., 1990. Quality of imported and domestic fruits and vegetables in the Danish retail trade with special reference to mechanical damage. Workshop on impact damage of ftuits and vegetables. Zaragoza. Vol.II pp. 9-16.

Robert, P., Bertrand, D., Crochon, M., Sabino, J., 1989. A new mathematical procedure for NIR analysis: The lattice technique. Application to the prediction of sugar content of apples. Appl. Spectroscopy 43 (6), 1576 GAL 76.

Rodriguez, L., Ruiz-Altisent, M., De Felipe, M.R., 1990. Differences in the structural response of Granny-Smith apples under mechanical impact and compression'. J. Texture Studies 21, 155-164.

Ros F., Brons, A., Sevila, F., Rabatel, G., Touzet, C., 1993. Combination of neural network and statistical methods for sensory evaluation of biological products: on-line beauty selection of flowers. Proceedings of the International Workshop on Artifcial Neural Networks, Spain, pp. 726-731.

Ruiz-Altisent, M., 1990. Impact parameters in relation to bruising and other fruit properties. Workshop on impact damage of fruits and vegetabies. FIMA. Zaragoza. Vol. II pp. 27-34.

Schulte, N.L., Brown, G.K., Timm, E.J., 1992. Apple impact damage threstolds. Appl. Engin. Agri. 8 (l), 55-60.

Schulte N., Timm, E., Brownn, G., 1993. Red Heaven peach impact damage thresholds. Fourth Int. Symp. Fruit, Nut and Vegetable Production Engineering Mechanization, Valencia/Zaragoza. Paper No. 935.18.

Sober, S.S., Zapp, H.R., Brown, G.K., 1990. Simulated packing line impacts for apple bruise prediction. Trans. ASAE $33(2), 629-636$.

Steinmetz, V., Delwiche, J., 1993. Neural network analysis of rose straightness. Int. Conf. for Agriculture and Food Equipment and Process control, Nimes, 253-263. 